\title{
Downregulation of microRNA-182 inhibits cell viability, invasion and angiogenesis in retinoblastoma through inhibition of the PI3K/AKT pathway and CADM2 upregulation
}

\author{
YAN-XIA HUANG ${ }^{1}$, XIN-GANG NIE ${ }^{1}$, GUANG-DA LI ${ }^{2}$, \\ DONG-SHENG FAN ${ }^{1}$, LI-LI SONG ${ }^{1}$ and XIN-LIN ZHANG ${ }^{1}$ \\ ${ }^{1}$ Department of Ophthalmology, Luoyang Central Hospital, Luoyang, Henan 471009; \\ ${ }^{2}$ Department of Ophthalmology, Linyi People's Hospital, Linyi, Shandong 276003, P.R. China \\ Received January 10, 2018; Accepted July 2, 2018
}

DOI: $10.3892 /$ ijo.2018.4587

\begin{abstract}
Retinoblastoma (RB) is a well-vascularized tumor dependent on angiogenesis. The present study aimed to explore whether microRNA (miR)-182 regulates cell viability, invasion and angiogenesis in $\mathrm{RB}$ via the phosphatidylinositol-3-OH kinase (PI3K)/protein kinase B (AKT) signaling pathway and by targeting cell adhesion molecule 2 (CADM2). The expression levels of miR-182 and CADM2 were initially detected in RB tissues from patients with RB who underwent ophthalmectomy, and normal retinal tissues collected from other trauma patients who underwent eye enucleation. To determine whether CADM2 was targeted by miR-182, a dual luciferase reporter assay was conducted. Subsequently, Y79 and WERI-Rb-1 $\mathrm{RB}$ cells were transfected with a miR-182 mimic or miR-182 inhibitor, or small interfering RNA against CADM2, in order to investigate the effects of miR-182 on viability and invasion, which were detected using MTT and Transwell assays, respectively. In addition, to determine whether the regulatory mechanism underlying the effects of miR-182 was associated with the PI3K/AKT signaling pathway, the expression levels of associated genes were detected by reverse transcription-quantitative polymerase chain reaction and western blot analysis. A xenograft tumor model in nude mice was also established, in order to evaluate the effects of miR-182 on tumor growth and angiogenesis. The results indicated that miR-182 expression was increased and CADM2 expression was reduced in RB tissues; CADM2 was confirmed to be targeted and negatively regulated by miR-182. When the expression of miR-182 was downregulated, cell viability, invasion, tumor volume and angiogenesis were significantly decreased. Furthermore, the
\end{abstract}

Correspondence to: Dr Xin-Gang Nie, Department of Ophthalmology, Luoyang Central Hospital, 288 Zhongzhouzhong Road, Xigong, Luoyang, Henan 471009, P.R. China

E-mail: niexingang@yeah.net

Key words: retinoblastoma, microRNA-182, CADM2, PI3K/AKT signaling pathway, angiogenesis, cell viability, invasion expression levels of PI3K/AKT signaling pathway-associated genes were increased in response to miR-182 overexpression or CADM2 silencing. Taken together, these results suggested that inhibition of miR-182 may suppress cell viability, invasion and angiogenesis in RB through inactivation of the PI3K/AKT pathway and CADM2 upregulation. This mechanism may reveal a novel potential therapeutic target.

\section{Introduction}

Retinoblastoma $(\mathrm{RB})$ is the most common type of primary intraocular cancer, which mainly occurs in children $<5$ years (1). It has been reported that RB comprises $\sim 11 \%$ of cancers that appear in the first year of life, with $95 \%$ diagnosed before 5 years of age (2). RB can be inherited in an autosomal dominant fashion caused by inactivation of the RB1 gene (3). RB presents with numerous symptoms, including abnormal appearance of the pupil, leukocoria, red and irritated eyes, deterioration of vision, faltering growth or delayed development (4). In addition, RB tumors exhibit perivascular sleeves composed of viable neoplastic cells and necrotic tissues, thus indicating that RB is closely associated with blood vessels (5). According to a previous study, microRNAs (miRNAs/miRs) serve a pivotal role in the development of $\mathrm{RB}$; therefore, further studies are required to investigate the role of miRNAs in RB (6).

miRNAs are a class of small non-coding RNAs that have vital roles in the regulation of target genes (7). miRNAs are involved in numerous physiological and pathological processes, including tumor development and exacerbation; aberrant miRNA expression has been observed in various types of cancer, including RB $(6,8,9)$. miR-182 is a member of the miR-183 cluster, which is located in the human chromosome $7 q 32$ region (10). Notably, miR-182 overexpression has been detected in numerous solitary malignancies, including ovarian cancer (11). Cell adhesion molecule 2 (CADM2), which is a member of the CADM family, is an immunoglobulin-like cell adhesion molecule (12). A previous study revealed that downregulation of epithelial cell adhesion molecule (a member of the CADM family) serves an essential role in the development of RB (13). The catalytic subunit of phosphatidylinositol-3-OH 
kinase (PI3K) can produce the phosphoinositide phosphates PIP2 and PIP3, which can activate several serine/threonine kinases, including protein kinase B (AKT) (14). AKT inhibits cell apoptosis by phosphorylating and inactivating the proapoptotic protein B-cell lymphoma 2 antagonist of cell death (15). The PI3K/AKT pathway is involved in cell growth, proliferation, survival and tumorigenesis (16), and according to a previous study, the development of $\mathrm{RB}$ is associated with activation of the PI3K/AKT pathway (17). However, there is currently limited data regarding the role of miR-182 in $\mathrm{RB}$ and its involvement with CADM 2 and the PI3K/AKT pathway. Therefore, the present study aimed to clarify how miR-182 regulates $\mathrm{RB}$, and its effects on the $\mathrm{PI} 3 \mathrm{~K} / \mathrm{AKT}$ pathway and CADM2.

\section{Materials and methods}

Ethics statement. Written informed consent was obtained from patients and their families prior to the study. The experiment was approved by the Ethics Committee of Luoyang Central Hospital (Luoyang, China). The animal studies conducted in the present study were approved by the Animal Care Committee at Luoyang Central Hospital.

Clinical sample collection. A total of $22 \mathrm{RB}$ samples were collected from patients with RB who underwent an ophthalmectomy at Luoyang Central Hospital between December 2012 and December 2016. Each sample was cut into 4-mm serial sections, and hematoxylin and eosin staining was used to verify the diagnosis. The patients enrolled consisted of 13 males and 9 females, aged between 3 months and 5 years, with no family history of RB (patients with a family history of RB were excluded). Of the patients, 17 had mono-ocular RB and 5 had binocular RB. Following surgery, fresh tumor tissues were immediately removed under aseptic conditions, fixed in formalin, automatically dehydrated, infiltrated with wax, embedded and sectioned. A total of 34 normal retinal tissue sections were collected from the patients who underwent eye enucleation following trauma.

Cell culture. Y79 and WERI-Rb-1 human RB cells were obtained from the cell repository of Shanghai Institute of Biochemistry and Cell Biology, Shanghai Institutes for Biological Sciences, Chinese Academy of Sciences (Shanghai, China). Y79 cells in a cryogenic vial were immediately placed in a water bath at a constant temperature of $37^{\circ} \mathrm{C}$, and the cryogenic vial was stirred to unfreeze and recover the cells as quickly as possible. The thawed Y79 cells were extracted with a pipette on a sterilized bench and placed in a centrifuge tube. Serum-free RPMI-1640 medium (cat. no. PM150110; Wuhan ProCell Life Science \& Technology Co., Ltd., Wuhan, China) was added to the centrifuge tube, in order to resuspend Y79 cells. The Y79 cells were then centrifuged at $376 \mathrm{x} \mathrm{g}$ for $5 \mathrm{~min}$ at $4^{\circ} \mathrm{C}$, after which, the supernatant was removed and the precipitation was washed 1-2 times. Subsequently, culture medium containing $15 \%$ fetal bovine serum (FBS, cat. no. 10099-141; Thermo Fisher Scientific, Inc., Waltham, MA, USA) was added and the cells were incubated at $37^{\circ} \mathrm{C}$ in an atmosphere containing $5 \% \mathrm{CO}_{2}$. WERI-Rb-1 cells were maintained in Dulbecco's modified Eagle's medium (DMEM) containing $10 \%$ FBS, penicillin $(100 \mu \mathrm{g} / \mathrm{ml})$ and streptomycin (100 $\mu \mathrm{g} / \mathrm{ml}$, Thermo Fisher Scientific, Inc.), at $37^{\circ} \mathrm{C}$ in an atmosphere containing $5 \% \mathrm{CO}_{2}$, and were conventionally passaged (18). Cells in the logarithmic growth phase were used for each experiment.

Dual luciferase reporter assay. A biology prediction website (microRNA.org) was used to analyze the target genes of miR-182 and to validate whether CADM2 is a target gene of miR-182. After searching the human target gene sequences in GenBank (National Institutes of Health, Bethesda, MA, USA; https://www.ncbi.nlm.nih.gov/genbank/), according to the results of the prediction analysis, the $3^{\prime}$ untranslated region (UTR) sequence of CADM2 was designed, and the one-step site-directed mutagenesis method (19) was applied to construct plasmid vectors containing CADM2-3'UTR wild-type (pCADM2-Wt) and CADM2-3'UTR mutant (pCADM2-Mut) sequences. Briefly, a double-stranded DNA fragment containing the target sequence of the wild/mutant 3' UTR was cloned into the XhoI/NotI site of the psiCHECK2 luciferase plasmid (cat. no. AY535006; Promega Corporation, Madison, WI, USA). Subsequently, miR-182 mimic negative control (NC) and miR-182 mimics (both from Shanghai GenePharma Co., Ltd, Shanghai, China), at a concentration of $40 \mathrm{nM}$, were separately co-transfected with pCADM2-Wt or pCADM2-Mut vectors at a concentration of $50 \mathrm{nM}$ into Y79 and WERI-Rb-1 $\left(2.5 \times 10^{5}\right.$ cells $\left./ \mathrm{ml}\right)$ at $37^{\circ} \mathrm{C}$ for $24 \mathrm{~h}$, according to the instructions of the Lipofectamine ${ }^{\circledR} 2000$ kit (cat. no. 11668-027; Invitrogen; Thermo Fisher Scientific, Inc.). The cells were thus assigned into the following four groups: miR-182 mimic + pCADM2-Wt, miR-182 mimic + pCADM2-Mut, miR-182 mimic NC + pCADM2-Wt and miR-182 mimic NC + pCADM2-Mut. The cells were incubated for $6 \mathrm{~h}$ at $37^{\circ} \mathrm{C}$ in an incubator containing $5 \% \mathrm{CO}_{2}$, after which the medium was removed and replaced with fresh medium. Following a 48-h incubation, the cells were lysed; to each well, $100 \mu 1$ passive lysis buffer (cat. no. 99912; Shanghai Open Biotechnology Co., Ltd., Shanghai, China) was added and the cells were agitated at low speed for $15 \mathrm{~min}$ and stored at $4^{\circ} \mathrm{C}$. A dual luciferase reporter assay was subsequently performed (cat. no. E1910; Inner Mongolia Hengsheng Biotechnological Co., Ltd., Inner Mongolia, China) according to the manufacturer's protocol. Luciferase assay reagent II (100 $\mu \mathrm{l})$ was added to $1.5 \mathrm{ml}$-Eppendorf tubes, and a luminometer (TD20/20; Turner Designs, San Jose, CA, USA) was used to visualize the tubes for 2 and $10 \mathrm{sec}$ before the addition of cell lysate. Subsequently, cell lysate $(20 \mu \mathrm{l})$ was added to the Eppendorf tubes and completely mixed before being placed on the luminometer to measure the activity of firefly luciferase (FLUC). Subsequently, $100 \mu 11 \mathrm{X}$ Stop\&Glo was added and completely mixed before being placed on the luminometer to measure the activity of Renilla luciferase (RLUC). The RLUC/FLUC ratio was calculated as the relative fluorescence activity, and applied to determine the target site of miRNA.

Cell transfection and grouping. Y79 and WERI-Rb-1 cells in logarithmic growth phase were inoculated in a 6-well culture plate at a concentration of $2 \times 10^{5}$ cells/well. Following adhesion of Y79 and WERI-Rb-1 cells, and once confluence reached $30-50 \%$, transfection was performed using the 
Lipofectamine ${ }^{\circledR} 2000$ kit (cat. no. 11668-027; Invitrogen; Thermo Fisher Scientific, Inc.), according to the manufacturer's protocol. A total of $100 \mu \mathrm{l}$ of each sequence was cloned into pcDNA3.1 plasmids (cat. no. V79020; Thermo Fisher Scientific, Inc.), which were then diluted in $250 \mu \mathrm{l}$ serum-free RPMI-1640 medium (the sequences were added to the cells at a final concentration of $50 \mathrm{nM}$ ), gently mixed and incubated at room temperature for $5 \mathrm{~min}$. In addition, $5 \mu$ l Lipofectamine ${ }^{\circledR} 2000$ was diluted with $250 \mu$ l serum-free RPMI-1640 medium, gently mixed and incubated at room temperature for $5 \mathrm{~min}$. The two mixtures were then mixed together, incubated at room temperature for $20 \mathrm{~min}$ and added to the cell culture wells. The cells $\left(2.5 \times 10^{5}\right.$ cells $\left./ \mathrm{ml}\right)$ were transfected for $48 \mathrm{~h}$. After transfection, the Y79 and WERI-Rb-1 cells were incubated for $4-6 \mathrm{~h}$ at $37^{\circ} \mathrm{C}$ in an incubator containing $5 \% \mathrm{CO}_{2}$ with saturated humidity, and the culture medium containing the transfection solution was discarded and replaced with RPMI-1640 containing FBS. The Y79 and WERI-Rb-1 cells were then incubated for 24-48 h for subsequent experiments. The Y79 and WERI-Rb-1 cells were assigned into the following seven groups: Blank group (without transfection), miR-182 mimic group (transfected with miR-182 mimic plasmid for $24 \mathrm{~h}$; transfection concentration, $50 \mathrm{nmol} / \mathrm{l}$ ), mimic NC group (transfected with miR-182 mimic $\mathrm{NC}$ plasmid for $24 \mathrm{~h}$; transfection concentration, $50 \mathrm{nmol} / \mathrm{l}$ ), miR-182 inhibitor group (transfected with miR-182 inhibitor plasmid for $24 \mathrm{~h}$; transfection concentration, $50 \mathrm{nmol} / \mathrm{l}$ ), inhibitor NC group (transfected with miR-182 inhibitor NC plasmid for $24 \mathrm{~h}$; transfection concentration, $50 \mathrm{nmol} / \mathrm{l}$ ), siCADM2 group [transfected with CADM2 small interfering (si)RNA plasmid, $50 \mathrm{nmol} / 1$ ] and miR-182 inhibitor + siCADM2 group (co-transfected with miR-182 inhibitor and CADM2 siRNA plasmid). The pcDNA3.1 plasmid was used as a vector. The sequences used for transfection were purchased from Shanghai GenePharma Co., Ltd. (Table I).

Reverse transcription quantitative polymerase chain reaction (RT-qPCR). Tissues (300 mg) or cells was collected and washed three times with PBS, after which total RNA was conventionally extracted using the TRIzol ${ }^{\circledR}$ one-step extraction method (cat. no. 15596-018; Invitrogen; Thermo Fisher Scientific, Inc.). The quality of total RNA was assessed and RNA concentration was adjusted. For the detection of U6 and miR-182, miRNA were reverse transcribed using stem-loop-mediated RT primers, which were synthesized by Shanghai Sangon Biotechnology Co., Ltd. (Shanghai, China). For the detection of genes, RNA was reverse transcribed into cDNA using the RevertAid First Strand cDNA Synthesis kit (Thermo Fisher Scientific, Inc.), according to the manufacturer's protocol. Briefly, RNA was gently agitated, centrifuged and incubated at $42^{\circ} \mathrm{C}$ for $60 \mathrm{~min}$, after which the samples were placed in a $70^{\circ} \mathrm{C}$ water bath for $5 \mathrm{~min}$ to terminate the RT reaction. The obtained cDNA was stored at $-80^{\circ} \mathrm{C}$. The mRNA expression levels of CADM2, PI3K, AKT, vascular endothelial growth factor (VEGF), Cyclin E, cyclin-dependent kinase (CDK)2, CDK4, Vimentin, matrix metalloproteinase (MMP)-9, snail family transcriptional repressor 1 (Snail) and GAPDH were determined based on the extracted RNA. Random hexamers were used as reverse primers. RT-qPCR was conducted using the TaqMan probe method (TaqMan-MGB; Shanghai Jianglin Biological Technology Co., Ltd., Shanghai, China),
Table I. Sequences used for transfection.

\begin{tabular}{ll}
\hline Plasmid & \multicolumn{1}{c}{ Sequence } \\
\hline miR-182 mimic & F: 5'-UUUGGCAAUGG \\
& UAGAACUCACACU-3' \\
& R: 5'-AGUGUGAGUUC \\
& UACCAUUGCCAAA-3' \\
miR-182 mimic NC & F: 5'-CCUGGUAAUGG \\
& UAGAAUCUACACU-3' \\
& R: 5'-AGUGUGAGUUC \\
miR-182 inhibitor & UACCAUUGCCAAA-3' \\
& 5'-AGUGUGAGUUCU \\
miR-182 inhibitor NC & ACCAUUGCCAAA-3' \\
& 5'-UAAUUCAAAAGA \\
CADM2 siRNA & CUAAAGGAAUCA-3' \\
& 5'-TACGTCCAAGGT \\
& CGGGCAGGAAGA-3'
\end{tabular}

miR-182, microRNA-182; NC, negative control; CADM2, cell adhesion molecule 2; siRNA, small interfering RNA; F, forward; R, reverse.

and the primer sequences are shown in Table II. The reaction conditions were as follows: Pre-denaturation at $95^{\circ} \mathrm{C}$ for $30 \mathrm{sec}$, followed by a total of 40 cycles of denaturation at $95^{\circ} \mathrm{C}$ for $10 \mathrm{sec}$, annealing at $60^{\circ} \mathrm{C}$ for $20 \mathrm{sec}$ and extension at $70^{\circ} \mathrm{C}$ for $10 \mathrm{sec}$, and a final extension step at $70^{\circ} \mathrm{C}$ for $10 \mathrm{~min}$. The reaction system contained 12.5 $\mu \mathrm{l}$ Premix Ex Taq or SYBR-Green Mix (cat. no. RR820A; Beijing Think Far Technology Co., Ltd., Beijing, China), $1 \mu$ l forward primer, $1 \mu \mathrm{l}$ reverse primer and 1-4 $\mu \mathrm{l}$ DNA template; $\mathrm{ddH}_{2} \mathrm{O}$ was used to make up the final volume of $25 \mu \mathrm{l}$. The measurements were performed using RT-qPCR apparatus (Bio-Rad iQ5; Bio-Rad Laboratories, Inc., Hercules, CA, USA). U6 was used as the internal reference gene for miR-182, whereas GAPDH was applied as the internal reference for the other genes. The $2^{-\Delta \Delta \mathrm{Cq}}$ method $(20,21)$ was employed to calculate the relative expression levels of miR-182, CADM2, PI3K, AKT, VEGF, Cyclin E, Vimentin, MMP-9 and Snail. The formula was as follows: $\Delta \Delta \mathrm{Cq}=\Delta \mathrm{Cq}_{\mathrm{RB} \text { group }}-\Delta \mathrm{Cq}_{\text {normal group }}$, $\Delta \mathrm{Cq}=\mathrm{Cq}_{\text {target gene }}-\mathrm{Cq}_{\mathrm{U} 6 / \mathrm{GAPDH}}$. The experiment was repeated independently three times.

Western blot analysis. The cells or tissues were collected, and $200 \mu \mathrm{l}$ pre-cooled radioimmunoprecipitation assay buffer (cat. no. R0020; Beijing Solarbio Science \& Technology Co., Ltd., Beijing, China) and $1 \mathrm{mmol} / \mathrm{l}$ phenylmethylsulfonyl fluoride were added for cell lysis with gentle agitation. The cells were well mixed using a pipette, and were disrupted for $30 \mathrm{~min}$ on ice. The protein lysates were transferred to a new centrifuge tube and spun at $2,414 \mathrm{x}$ g for $5 \mathrm{~min}$ at $4^{\circ} \mathrm{C}$. The proteins in the supernatant were extracted and protein concentration was measured using the Bicinchoninic Acid Protein Quantification kit (Wuhan Boster Biological Technology, Ltd., Wuhan, China), according to the manufacturer's protocol. Extracted proteins (30 $\mu \mathrm{g} /$ well) were subsequently added to sample buffer and boiled at $95^{\circ} \mathrm{C}$ for $10 \mathrm{~min}$. The proteins were separated by $10 \%$ PAGE, after which they 
Table II. Reverse transcription-quantitative polymerase chain reaction primer sequences.

\begin{tabular}{ll}
\hline Gene & \multicolumn{1}{c}{ Primer sequence } \\
\hline miR-182 & F: 5'-TGCGGTTTGGCAATGGTAGAAC-3' \\
& R: 5'-CCAGTGCAGGGTCCGAGGT-3' \\
U6 & F: 5'-TGCGGGTGCTCGCTTCGGCAGC-3' \\
& R: 5'-CCAGTGCAGGGTCCGAGGT-3' \\
CADM2 & F: 5'-AAACCGGTCGCCACCATGATTTG \\
& GAAACGCAGC-3' \\
& R: 5'-AAATCGATTAAATGAAATACTCTT \\
& TTTTCTC-3' \\
PI3K & F: 5'-TTTCTCATGGCTGTCCTTCAG-3' \\
& R: 5'-CAGGAGAATCTAACGGATGC-3' \\
AKT & F: 5'-CATCACATCTGGTTTCCTTGG-3' \\
& R: 5'-AACTGGAAATGTAATTTTGGG-3' \\
VEGF & F: 5'-CAGCCCCAGCTACCACCTC-3' \\
& R: 5'-TCTTCCTCCTCCCCTCCTC-3' \\
CDK2 & F: 5'-CCTTGTTTGTCCCTTCTAC-3' \\
& R: 5'-CAAATCCACCCACTATGA-3' \\
CDK4 & F: 5'-CATGTAGACCAGGACCTAAGC-3' \\
& R: 5'-AACTGGCGCATCAGATCCTAG-3' \\
MMP-9 & F: 5'-CACTGTCCACCCCTCAGAGC-3' \\
& R: 5'-GCCACTTGTCGGCGATAAGG-3' \\
Snail & F: 5'-CTCCTCTACTTCAGCCTCTT-3' \\
Vimentin & R: 5'-CTTCATCAACGTCCTGTGGG-3' \\
Fyclin E & F: 5'-AAAGTGTGGCTGCCAAGAAC-3' \\
GAPDH & R: 5'-AGCCTCAGAGAGGTCAGCAA-3' \\
& R: 5'-GTTCCATTTGCAAAGGCTGT-3' \\
& F: 5'-TGGTGAAGGTCGGTGTGAAC-3' \\
& R: 5'-GCTCCTGGAAGATGGTGATGG-3' \\
\hline
\end{tabular}

miR-182, microRNA-182; CADM2, cell adhesion molecule 2; AKT, rotein kinase B; CDK2, cyclin-dependent kinase; MMP-9, matrix metalloproteinase-9; PI3K, phosphoinositide 3-OH kinase; VEGF, vascular endothelial growth factor; Snail, snail family transcriptional repressor 1; F, forward; R, reverse.

were transferred onto polyvinylidene difluoride membranes (cat. no. P2438; Sigma-Aldrich; Merck KGaA, Darmstadt, Germany) using semi-dry electro-transfer, and blocked with $5 \%$ milk at room temperature for $1 \mathrm{~h}$. Subsequently, the membranes were incubated with the following primary antibodies overnight at $4^{\circ} \mathrm{C}$ : Rabbit-anti-CADM2 (1:1,000, cat. no. ab64873), rabbit-anti-PI3K (1:500, cat. no. ab191606), rabbit-anti-AKT (1:500, cat. no. ab8805), rabbit-anti-VEGF $(1: 5,000$, cat. no. ab53465), rabbit-anti-Vimentin (1:1,000, cat. no. ab45939), rabbit-anti-MMP-9 (1:1,000, cat. no. ab73734), rabbit-anti-Snail (1:333, cat. no. ab82846), rabbit-anti-CDK2 (1:1,000, cat. no. ab32147), rabbit-anti-CDK4 (1:1,000, cat. no. ab108357), rabbit-anti-Cyclin E (1:1,000, cat. no. ab88259) and rabbit-anti-GAPDH $(1: 2,500$, cat. no. ab9485), which was used as a control (all from Abcam, Cambridge, MA, USA). The membranes were washed three times with Tris-buffered saline with $0.05 \%$ Tween-20 (5 min/wash), and a goat anti-rabbit secondary antibody $(1: 2,000$, cat. no. ab6721; Abcam) was added and incubated for $1 \mathrm{~h}$ at room temperature. The membranes were then washed a further three times ( $5 \mathrm{~min} / \mathrm{wash}$ ). Chemiluminescent reagents (Shanghai Yanhui Biological Technology Co., Ltd., Shanghai, China) were used for visualization, and GAPDH served as an internal reference. Bio-Rad Gel Doc EZ imager (Bio-Rad Laboratories, Inc.) was applied to develop the image, and ImageJ software v1.8.0 (National Institutes of Health) was employed to analyze the gray values of the target bands; the relative protein expression levels were calculated using the ratio of the gray values of the target band and the internal reference band. The experiment was repeated independently three times.

MTT assay. After $12 \mathrm{~h}$ transfection, Y79 and WERI-Rb-1 cells were washed with PBS twice, detached using $0.25 \%$ trypsin and a single cell suspension was generated. The cells were counted and then inoculated into a $96-$-well plate at a density of $3-6 \times 10^{3}$ cells/well. The volume in each well was $200 \mu 1$, including the blank well, with 6 parallel wells in each plate. The cells were cultured in an incubator with constant humidity at $37^{\circ} \mathrm{C}$ and $5 \% \mathrm{CO}_{2}$; the 96-well plate was removed from the incubator at a fixed time each day. After 24 and 48 h, $20 \mu \mathrm{l}$ $5 \mathrm{mg} / \mathrm{ml}$ MTT solution (cat. no. A2776-lg; Shanghai Shifeng Biological Technology Co.,Ltd., Shanghai, China) was added to each well. Following a $4-\mathrm{h}$ incubation at $37^{\circ} \mathrm{C}$, the medium was discarded, $150 \mu 1$ dimethyl sulfoxide was added to each well and the plates were incubated at room temperature with gently agitation for $10 \mathrm{~min}$. The optical density (OD) was measured at $570 \mathrm{~nm}$ using an enzyme-linked immunometric meter at 24 and $48 \mathrm{~h}$. Subsequently, the cell viability curve was generated with time as the $\mathrm{x}$-axis label and OD value as the $\mathrm{y}$-axis label; cell viability was compared between the experimental groups (the miR-182 mimic, mimic NC, miR-182 inhibitor, inhibitor NC, siCADM2 and miR-182 inhibitor + siCADM2 groups) and the blank wells. The experiment was repeated independently three times.

Transwell assay. Matrigel (cat. no. 40111ES08; Shanghai Yesen Biological Technology Co., Ltd., Shanghai, China) was dissolved at $4{ }^{\circ} \mathrm{C}$ overnight and diluted with DMEM at a ratio of 1:3. A total of $30 \mu \mathrm{l}$ diluted Matrigel was added to the apical chamber of each Transwell system in three separate additions $(15,7.5$ and $7.5 \mu \mathrm{l})$ with a 10 -min interval between each. The Matrigel was evenly laid and covered all of the micropores on the bottom of the apical chamber. After a 48-h transfection, Y79 and WERI-Rb-1 cells from each group were collected, and a cell suspension at a final concentration of $1 \times 10^{6}$ cells $/ \mathrm{ml}$ was prepared, which was inoculated into the apical chamber of the Transwell chamber. DMEM containing 10\% FBS was added into the basolateral chamber, and the cells incubated for $48 \mathrm{~h}$ at $37^{\circ} \mathrm{C}$ and $5 \% \mathrm{CO}_{2}$. Swabs were used to gently remove non-penetrating cells in the apical chamber. The membrane was then removed, fixed with 95\% ethanol for 15-20 min, immersed in water and then stained with $1 \mathrm{mg} / \mathrm{l}$ methyl violet for $10 \mathrm{~min}$ at $37^{\circ} \mathrm{C}$. The membrane was immersed in water and observed under high magnification with an inverted microscope. A total of five high-power fields of view were selected from each sample 

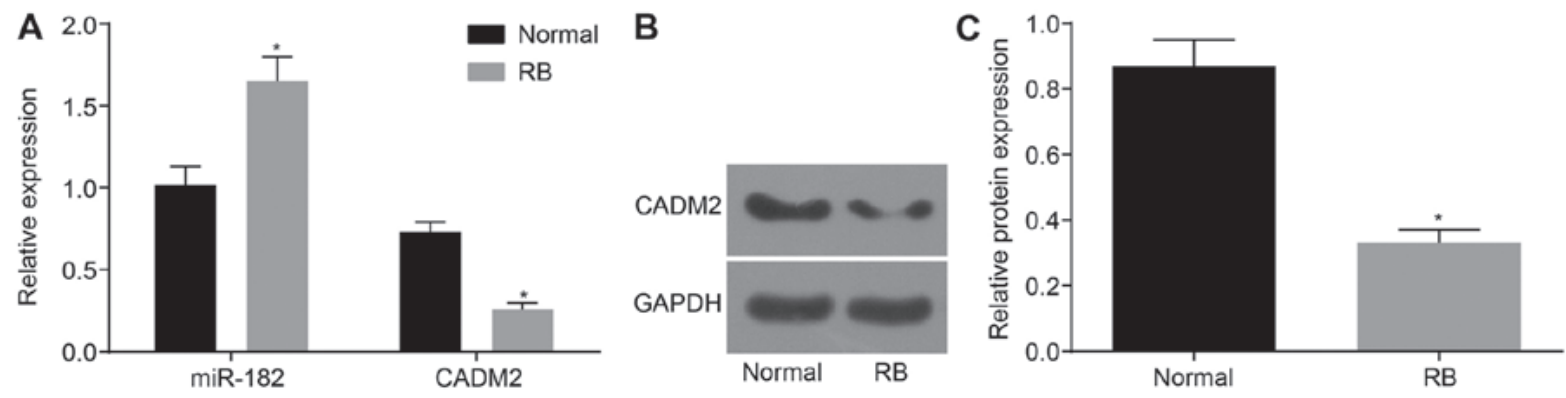

Figure 1. miR-182 expression is increased and CADM2 expression is decreased in RB retinal tissues, as determined by RT-qPCR and western blot analysis (A) RT-qPCR was applied for the determination of miR-182 expression and CADM2 mRNA expression in normal and RB retinal tissues. (B) Western blot analysis provided the gray values of the CADM2 protein bands. (C) CADM2 protein expression was reduced in RB retinal tissues compared with in normal retinal tissues, as determined by western blot analysis. ${ }^{*} \mathrm{P}<0.05$ compared with the normal group. Data are presented as the means \pm standard deviation. Student's t-test was used for data analysis. The experiment was repeated independently three times. miR-182, microRNA-182; CADM2, cell adhesion molecule 2; RB, retinoblastoma; RT-qPCR, reverse transcription-quantitative polymerase chain reaction.

to count the cells and calculate the mean values. The number of cells that invaded through the Matrigel in each group was used as an index to evaluate their invasive ability. The experiment was repeated independently three times.

Xenograft tumor model in nude mice. A total of $70 \mathrm{BALB} / \mathrm{c}$ nude mice (cat. no. J004; Nanjing Junke Biological Engineering Co., Ltd., Nanjing, China; age, 5 weeks; weight, 18-22 g) were housed under specific-pathogen-free conditions: temperature, $18-22^{\circ} \mathrm{C}$; humidity, 50-60\%; ammonia concentration, $\leq 20 \mathrm{ppm}$; and ventilation rate, 10-20 times/h. The mice were given free access to sterilized food/water and were maintained under a 10-h light/14-h dark cycle. The nude mice were randomly allocated into the following seven groups: Blank group (mouse model of RB was established using untransfected Y79 and WERI-Rb-1 cells), miR-182 mimic group (mice were injected with Y79 and WERI-Rb-1 cells transfected with miR-182 mimic sequence), mimic NC group (mice were injected with Y79 and WERI-Rb-1 cells transfected with miR-182 mimic NC sequence), miR-182 inhibitor group (mice were injected with Y79 and WERI-Rb-1 cells transfected with miR-182 inhibitor sequence), inhibitor NC group (mice were injected with Y79 and WERI-Rb-1 cells transfected with miR-182 inhibitor NC sequence), siCADM2 (mice were injected with Y79 and WERI-Rb-1 cells transfected with CADM2 siRNA sequence) and miR-182 inhibitor + siCADM2 group (mice were injected with Y79 and WERI-Rb-1 cells transfected with miR-182 inhibitor and CADM2 siRNA sequences) ( $\mathrm{n}=10$ mice/group; male and female, 1:1). After $24 \mathrm{~h}$ transfection, cells were treated with $0.25 \%$ trypsin and a cell suspension was generated, with the cell density adjusted to $1 \times 10^{5}$ cells $/ \mathrm{ml}$. Local skin disinfection was performed and $0.5 \mathrm{ml}$ cell suspension was subcutaneously injected into the right foreleg of each mouse. During injections, the needle was cautiously inserted under the skin and slowly extracted. Following extraction of the needle, slight pressure was placed onto the injection site for $30 \mathrm{sec}$, in order to prevent leakage of the cell suspension. The general condition of the nude mice and the local condition of the inoculation site were observed. All nude mice were sacrificed under deep anesthesia with pentobarbital sodium $(100 \mathrm{mg} / \mathrm{kg})$ 5 weeks post-inoculation, and gross tumor size was observed and tumor weight was measured.
Immunohistochemistry. Tumor specimens were fixed with neutral-buffered formalin, dehydrated, embedded in paraffin, serially sectioned at $5 \mu \mathrm{m}$ and dehydrated. The sections were then treated with $3 \%$ hydrogen peroxide at room temperature for $10 \mathrm{~min}$ and underwent heated antigen retrieval with sodium citrate antigen repair solution (cat. no. IH0305; Beijing Leagene Biotech Co., Ltd., Beijing, China) in a water bath. The subsequent experiment was not conducted until the buffer was heated to boiling. The sections were sealed with normal nonimmune mouse serum (cat. no. GD-MY595J; Shanghai Guduo Biotechnology Co., Ltd., Shanghai, China) at room temperature for $3 \mathrm{~h}$. A cluster of differentiation (CD) 34 rabbit polyclonal primary antibody (1:200, cat. no. ab185732; Abcam) was added to the sections and incubated at $4{ }^{\circ} \mathrm{C}$ overnight, followed by incubation with a biotin-labeled goat anti-rabbit immunoglobulin $\mathrm{G}$ secondary antibody $\left(1: 2,000\right.$, cat. no. ab6720; Abcam) at $37^{\circ} \mathrm{C}$ for $20 \mathrm{~min}$. DAB (BIOSS, Beijing, China) was applied for development. The sections were counterstained with hematoxylin, dehydrated, cleared, mounted and observed under a confocal microscope. According to CD34 expression, the number of microvessels in each of the 10 fields of view was counted, and the mean microvessel density (MVD) was calculated.

Statistical analysis. The experiments were repeated three times. SPSS software version 21.0 (IBM Corp., Armonk, NY, USA) was used for data analysis. Measurement data are presented as the means \pm standard deviation. Student's t-test was applied for comparisons between two groups. The Kolmogorov-Smirnov method was used to test normality of data, and one-way analysis of variance and Tukey's post hoc test were used for comparisons among multiple groups with normal distribution. The non-parametric Kruskal-Wallis method was used to analyze data with skewed distribution, and Dunn's multiple comparison post hoc test was performed. $\mathrm{P}<0.05$ was considered to indicate a statistically significant difference.

\section{Results}

miR-182 is upregulated and CADM2 is downregulated in $R B$ retinal tissue. The expression levels of CADM 2 mRNA and protein and miR-182 were measured by RT-qPCR and western blot analysis. As shown in Fig. 1A, miR-182 expression was increased in $\mathrm{RB}$ retinal tissues compared 

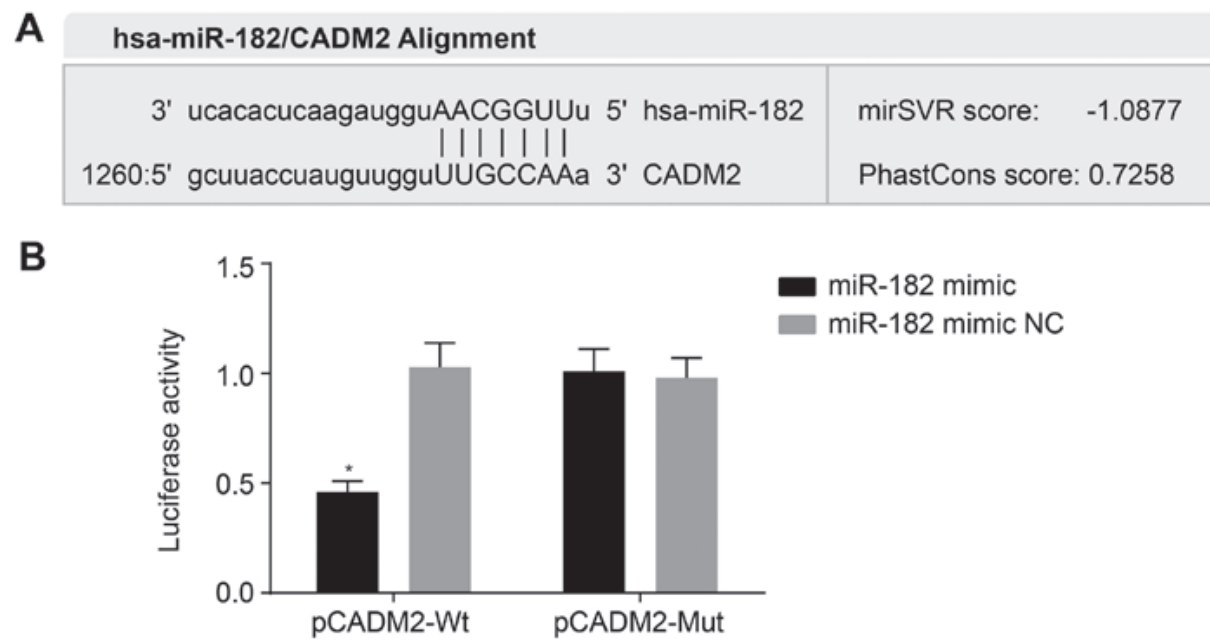

Figure 2. miR-182 targets the 3' untranslated region of CADM2. (A) microRNA.org predicted that miR-182 targeted CADM2. (B) Luciferase reporter assay confirmed that CADM2 is a target of miR-182. " $\mathrm{P}<0.05$ compared with the miR-182 mimic NC + pCADM2-Wt group. Luciferase activity data are expressed as the means \pm standard deviation. Student's t-test was used for data analysis. The experiment was repeated independently three times. miR-182, microRNA-182; CADM2, cell adhesion molecule 2; Mut, mutant; NC, negative control; Wt, wild-type.
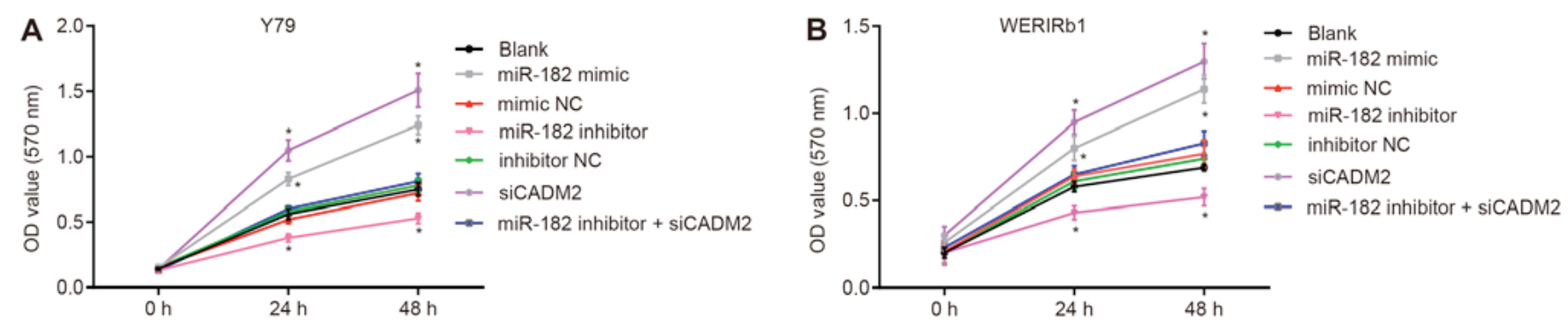

Figure 3. Y79 and WERI-Rb-1 cell viability is enhanced by miR-182 overexpression or CADM2 silencing, as determined by MTT assay. (A) Y79 cell viability after 24 and $48 \mathrm{~h}$ transfection was determined by MTT assay. (B) WERI-Rb-1 cell viability after 24 and $48 \mathrm{~h}$ transfection was determined by MTT assay. " $\mathrm{P}<0.05$ compared with the blank group. OD values are presented as the means \pm standard deviation. One-way analysis of variance and Tukey's post hoc test was conducted to compare cell viability at different time-points. The experiment was repeated independently three times. miR-182, microRNA-182; CADM2, cell adhesion molecule 2; NC, negative control; OD, optical density; siCADM2, CADM2 small interfering RNA.

with in normal retinal tissues $(\mathrm{P}<0.05)$. In addition, in $\mathrm{RB}$ retinal tissues, the mRNA and protein expression levels of CADM2 were decreased compared with in normal retinal tissues $(\mathrm{P}<0.05$; Fig. 1B and $\mathrm{C})$. These results indicated that the expression levels of miR-182 were upregulated, whereas CADM2 was downregulated in RB retinal tissue.

miR-182 binds to the 3'UTR of CADM2. The relationship between miR-182 and CADM2 was predicted by microRNA.org and confirmed using the dual luciferase reporter assay. microRNA.org revealed that miR-182 targeted CADM2 (Fig. 2A). The results of a dual luciferase reporter assay (Fig. 2B) demonstrated that the luciferase signal was decreased by $\sim 53 \%$ in the miR-182 mimic + pCADM2-Wt group compared with the miR-182 mimic NC + pCADM2-Wt group $(\mathrm{P}<0.05)$, whereas there were no differences in the luciferase signal between the miR-182 mimic + pCADM2-Mut and miR-182 mimic $\mathrm{NC}+$ pCADM2-Wt or miR-182 mimic NC + pCADM2-Mut groups $(\mathrm{P}>0.05)$. These results indicated that miR-182 may target and negatively regulate CADM2 expression.

miR-182 overexpression or CADM2 silencing promotes $Y 79$ and WERI-Rb-1 cell viability. Cell viability was measured using the
MTT assay (Fig. 3). In human RB Y79 and WERI-Rb-1 cells 24 and $48 \mathrm{~h}$ post-transfection, compared with the blank group, the miR-182 mimic and siCADM2 groups exhibited significantly elevated cell viability $(\mathrm{P}<0.05)$, whereas cell viability was reduced in the miR-182 inhibitor group $(\mathrm{P}<0.05)$. There was no difference in cell viability among the blank, mimic $\mathrm{NC}$, inhibitor NC and miR-182 inhibitor + siCADM2 groups $(\mathrm{P}>0.05)$. These findings suggested that cell viability may be promoted by miR-182 overexpression or CADM2 silencing.

miR-182 overexpression or CADM2 silencing promotes Y79 and WERI-Rb-1 cell invasion. In order to assess the invasive ability of RB retinal cells, a Transwell assay was conducted. As shown in Fig. 4, following 48-h culture of Y79 and WERI-Rb-1 cells, compared with the blank group, the miR-182 mimic and siCADM2 groups exhibited a significantly elevated number of invasive cells, whereas the number of invasive cells was reduced in the miR-182 inhibitor group $(\mathrm{P}<0.05)$. There was no difference in the number of invasive cells among the blank, mimic NC, inhibitor NC and miR-182 inhibitor + siCADM2 groups $(\mathrm{P}>0.05)$. These findings indicated that cell invasion may be promoted by miR-182 overexpression or CADM2 silencing. 
A
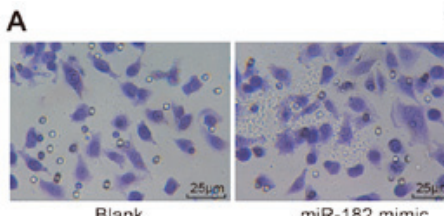

Y79
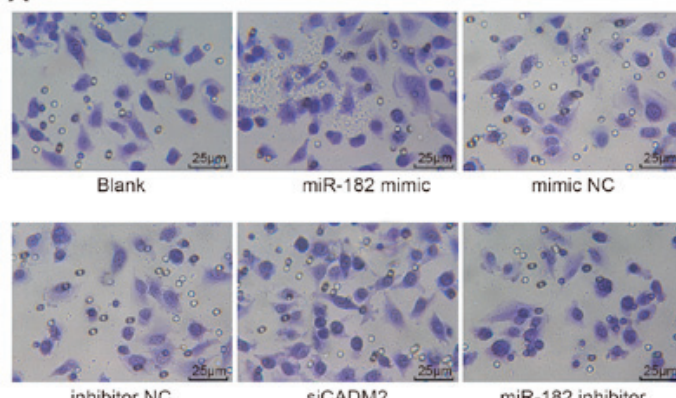

inhibitor NC

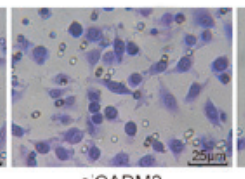

siCADM2

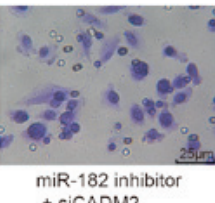

miR-182 innibition
+ siCADM
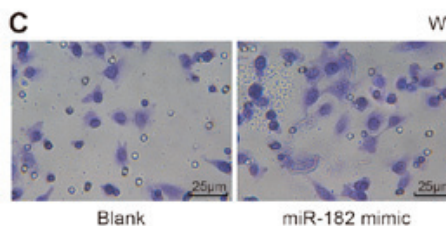

WERIRb1
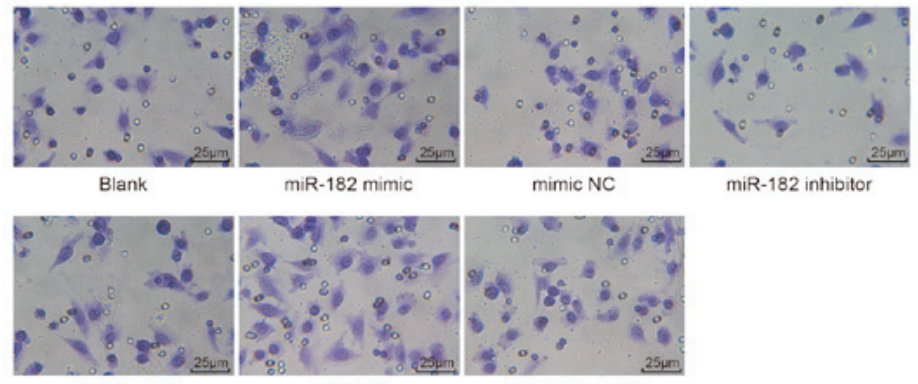

inhibitor NC

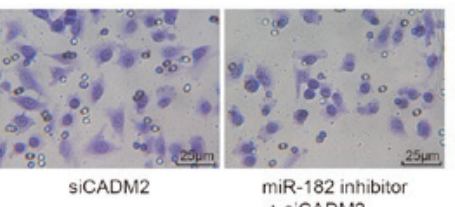

miR-182 inhibitor
+ siCADM2
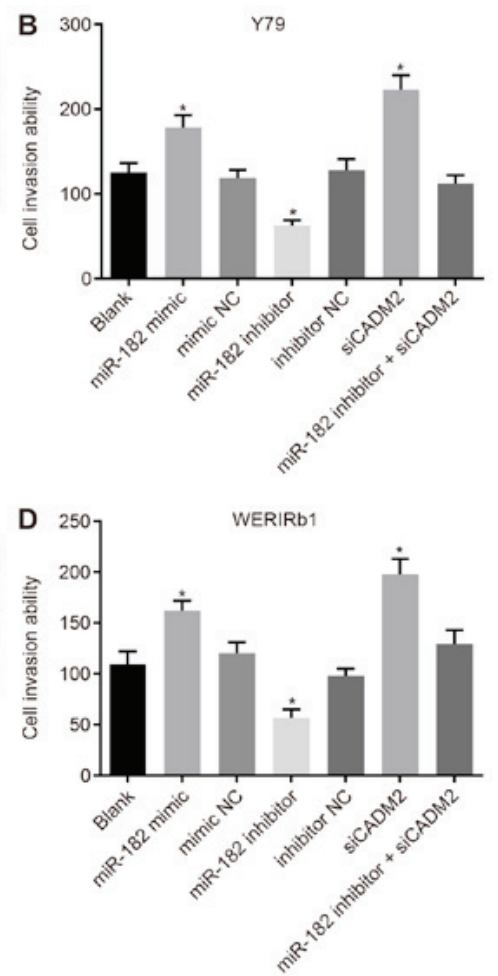

Figure 4. Y79 and WERI-Rb-1 cell invasion is enhanced by miR-182 overexpression or CADM2 silencing, as determined using a Transwell assay. (A) Y79 cell invasion post-transfection was detected by a Transwell assay. (B) Number of invasive Y79 cells was promoted by miR-182 overexpression or CADM2 silencing. (C) WERI-Rb-1 cell invasion post-transfection was detected by a Transwell assay. (D) Number of invasive WERI-Rb-1 cells was promoted by miR-182 overexpression or CADM2 silencing. "P $<0.05$ compared with the blank group. The enumeration data are presented as the means \pm standard deviation. One-way analysis of variance and Tukey's post hoc test was used to compare experimental groups. The experiment was repeated independently three times. miR-182, microRNA-182; CADM2, cell adhesion molecule 2; NC, negative control; siCADM2, CADM2 small interfering RNA.

A

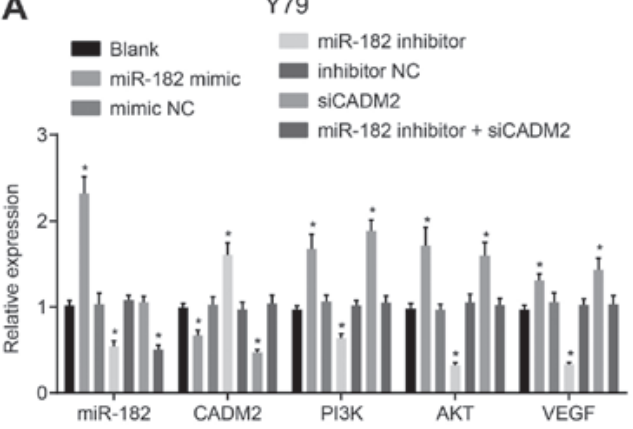

B

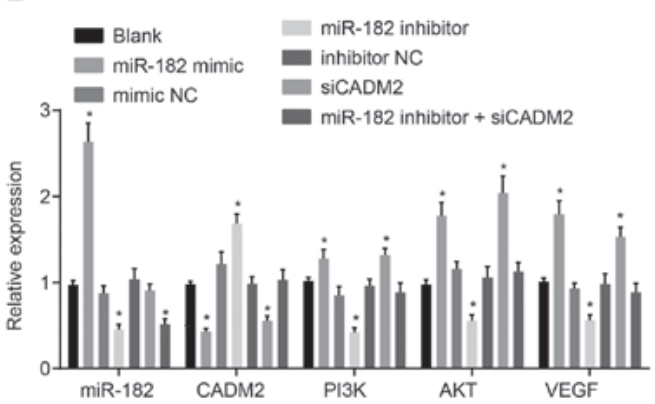

Y79

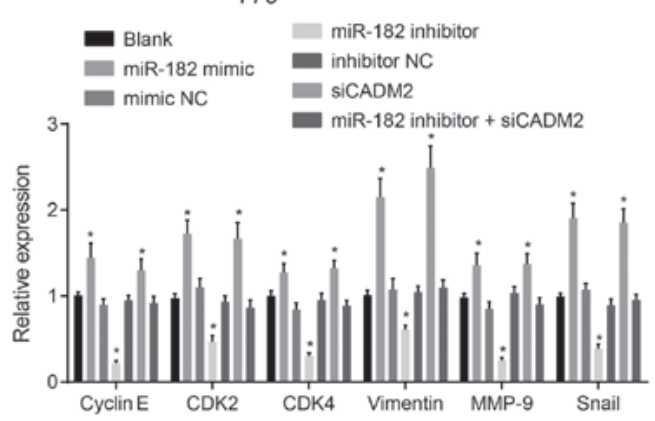

WERIRb1

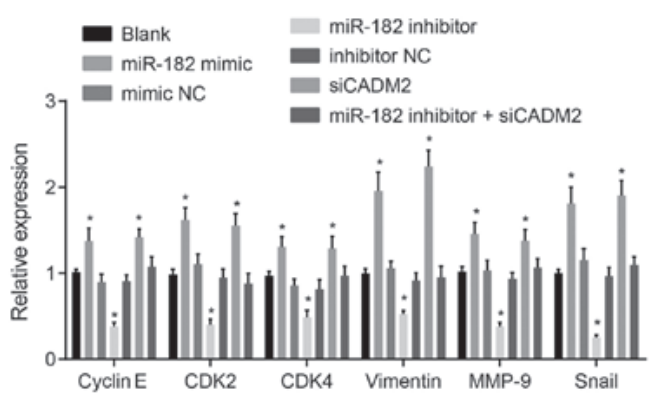

Figure 5. mRNA expression levels of PI3K/AKT pathway-, angiogenesis-, proliferation- and invasion-associated genes are increased by miR-182 overexpression or CADM2 silencing, as determined by reverse transcription-quantitative polymerase chain reaction. (A) mRNA expression levels of PI3K, AKT, VEGF, Cyclin E, CDK2, CDK4, Vimentin, MMP-9 and Snail were increased in Y79 cells in response to miR-182 overexpression or CADM2 silencing. (B) mRNA expression of PI3K, AKT, VEGF, Cyclin E, CDK2, CDK4, Vimentin, MMP-9 and Snail was increased in WERI-Rb-1 cells in response to miR-182 overexpression or CADM2 silencing. " $\mathrm{P}<0.05$ compared with the blank group. The measurement data are presented as the means \pm standard deviation, and were analyzed by one-way analysis of variance and Tukey's post hoc test. The experiment was repeated independently three times. AKT, protein kinase B; miR-182, microRNA-182; CADM2, cell adhesion molecule 2; CDK, cyclin-dependent kinase; MMP-9, matrix metalloproteinase-9; NC, negative control; PI3K, phosphoinositide 3-OH kinase; siCADM2, CADM2 small interfering RNA; Snail, snail family transcriptional repressor 1; VEGF, vascular endothelial growth factor. 
A
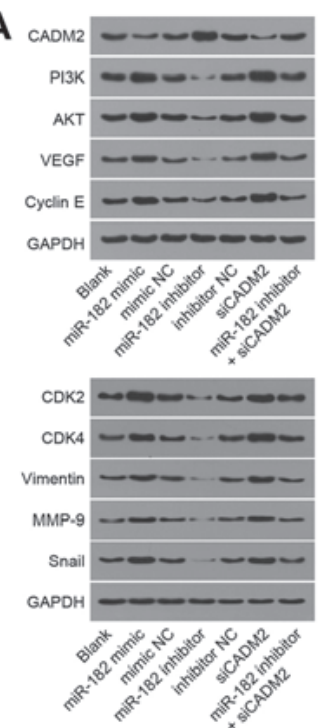
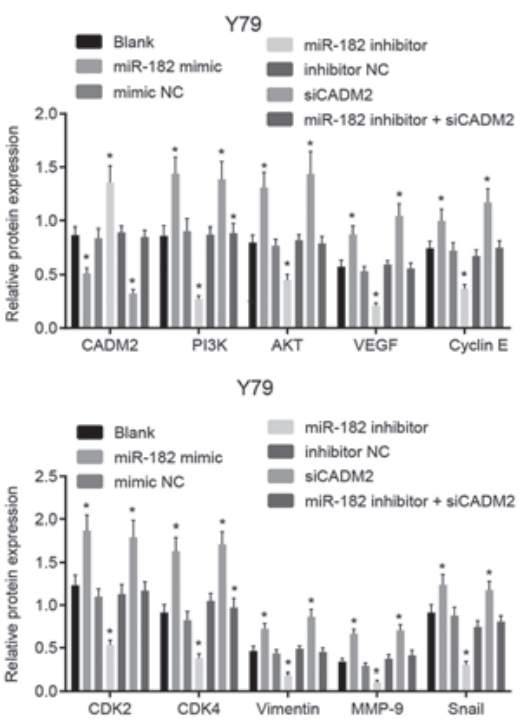

B
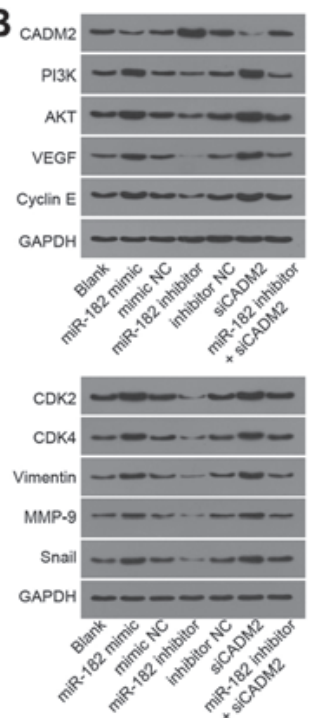

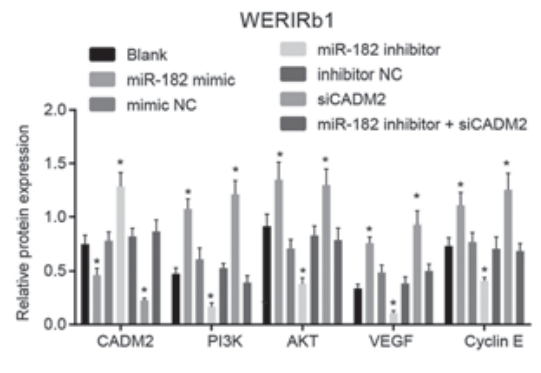

WERIRb1

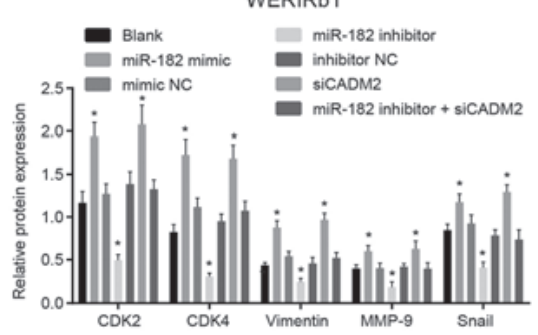

Figure 6. Expression levels of PI3K/AKT pathway-, angiogenesis-, viability- and invasion-associated proteins are increased by miR-182 overexpression or CADM2 silencing, as determined by western blot analysis. (A) Protein expression levels of PI3K, AKT, VEGF, Cyclin E, CDK2, CDK4, Vimentin, MMP-9 and Snail were increased in Y79 cells by miR-182 overexpression or CADM2 silencing. (B) Protein expression levels of PI3K, AKT, VEGF, Cyclin E, CDK2, CDK4, Vimentin, MMP-9 and Snail were increased in WERI-Rb-1 cells by miR-182 overexpression or CADM2 silencing. * $<0.05$, compared with the blank group. The measurement data are presented as the means \pm standard deviation, and were analyzed by one-way analysis of variance and Tukey's post hoc test. The experiment was repeated independently three times. AKT, protein kinase B; miR-182, microRNA-182; CADM2, cell adhesion molecule 2; CDK, cyclin-dependent kinase; MMP-9, matrix metalloproteinase-9; NC, negative control; PI3K, phosphoinositide 3-OH kinase; siCADM2, CADM2 small interfering RNA; Snail, snail family transcriptional repressor 1; VEGF, vascular endothelial growth factor.

miR-182 overexpression or CADM2 silencing increases the mRNA expression levels of PI3K, AKT, VEGF, Cyclin E, $C D K 2, C D K 4$, Vimentin, MMP-9 and Snail. RT-qPCR was used to measure miR-182 expression and the mRNA expression levels of CADM2, PI3K/AKT pathway-associated genes (PI3K and AKT), an angiogenesis-associated gene (VEGF), proliferation-associated genes (Cyclin E, CDK2 and CDK4) and invasion-associated genes (Vimentin, MMP-9 and Snail) in Y79 and WERI-Rb-1 cells post-transfection. As shown in Fig. 5, compared with the blank group, in the miR-182 mimic group, miR-182 expression was significantly elevated, whereas in the miR-182 inhibitor and miR-182 inhibitor + siCADM2 groups, miR-182 expression was reduced $(\mathrm{P}<0.05)$. There was no difference in miR-182 expression among the mimic NC, inhibitor $\mathrm{NC}$ and siCADM2 groups $(\mathrm{P}>0.05)$. The mRNA expression levels of CADM2 were significantly decreased in the miR-182 mimic and siCADM2 groups, whereas the mRNA expression levels of PI3K, AKT, VEGF, Cyclin E, CDK2, CDK4, Vimentin, MMP-9 and Snail were increased $(\mathrm{P}<0.05)$. In the miR-182 inhibitor group, an increase in CADM2 mRNA expression was observed, whereas PI3K, AKT, VEGF, Cyclin E, CDK2, CDK4, Vimentin, MMP-9 and Snail were decreased $(\mathrm{P}<0.05)$. There was no difference in the expression of the aforementioned genes among the blank, mimic $\mathrm{NC}$, inhibitor NC and miR-182 inhibitor + siCADM2 groups $(\mathrm{P}>0.05)$. These findings revealed that the PI3K/AKT pathway may be activated in response to miR-182 overexpression or CADM2 silencing, which may contribute to enhancement of angiogenesis, viability and invasion.

miR-182 overexpression or CADM2 silencing increases the protein expression levels of PI3K, AKT, VEGF, Cyclin E, CDK2, CDK4, Vimentin, MMP-9 and Snail. Western blot analysis was conducted on Y79 and WERI-Rb-1 cells to determine the protein expression levels of PI3K, AKT, VEGF, Cyclin E, CDK2, CDK4, Vimentin, MMP-9 and Snail. As shown in Fig. 6, compared with the blank group, the miR-182 mimic and siCADM2 groups exhibited significantly reduced expression of CADM2, and elevated PI3K, AKT, VEGF, Cyclin E, CDK2, CDK4, Vimentin, MMP-9 and Snail expression $(\mathrm{P}<0.05)$. An opposite trend was detected in the miR-182 inhibitor group, which exhibited upregulation of CADM2 protein expression, and decreased expression of PI3K, AKT, VEGF, Cyclin E, CDK2, CDK4, Vimentin, MMP-9 and Snail $(\mathrm{P}<0.05)$. There was no difference in the protein expression levels of PI3K and AKT among the blank, mimic NC, inhibitor $\mathrm{NC}$ and miR-182 inhibitor + siCADM2 groups $(\mathrm{P}>0.05)$. These findings revealed that the PI3K/AKT pathway may be activated by miR-182 overexpression or CADM2 silencing, which may contribute to enhancement of angiogenesis, viability and invasion.

miR-182 overexpression or CADM2 silencing promotes tumor growth in nude mice inoculated with Y79 and WERI-Rb-1 cells post-transfection. A xenograft tumor model was generated in nude mice to analyze whether miR-182 could affect the growth of $\mathrm{RB}$ by regulating CADM2 in vivo. Following a tumor incubation period of $\sim 7$ days, the inoculation site of all nude mice possessed tumors visible to the naked eye; at the inoculation site, subcutaneous nodules were oval at the beginning and gradually became irregular with a lobulated concavo-convex surface. The tumor formation rate was $100 \%$. After 5 weeks, the nude mice were sacrificed once ulceration was observed on the tumor surface. The tumor was removed and weighed, and the tumor volume was calculated. Compared with the blank group, the miR-182 mimic and siCADM2 groups exhibited 

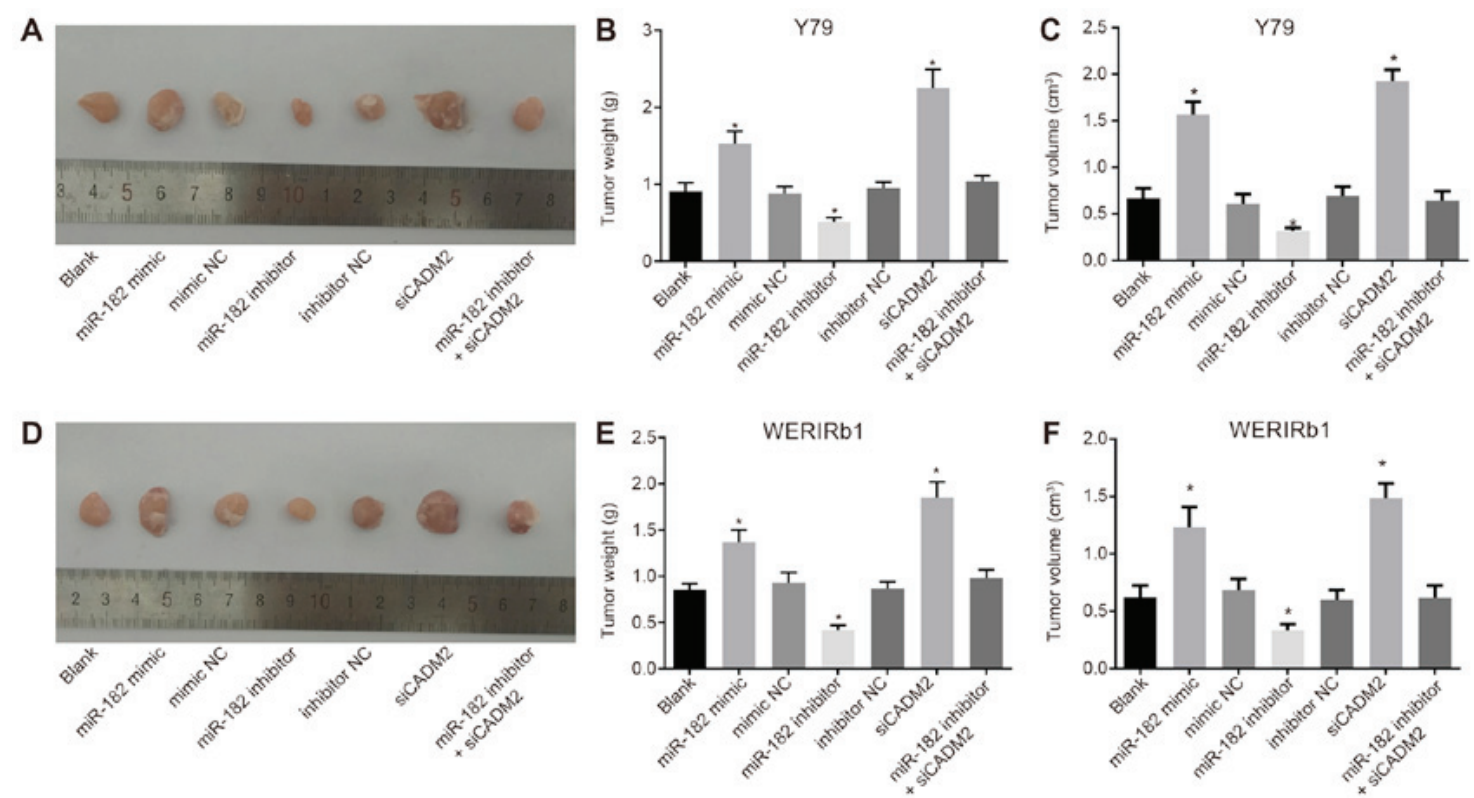

Figure 7. Tumor growth is promoted by miR-182 overexpression and CADM2 silencing following inoculation of Y79 and WERI-Rb-1 cells post-transfection (A) Tumor morphology of nude mice inoculated with Y79 cells in each group. (B) Tumor weight of nude mice inoculated with Y79 cells in each group. (C) Tumor volume of nude mice inoculated with Y79 cells in each group. (D) Tumor morphology of nude mice inoculated with WERI-Rb-1 cells in each group. (E) Tumor weight of nude mice inoculated with WERI-Rb-1 cells in each group. (F) Tumor volume of nude mice inoculated with WERI-Rb-1 cells in each group. "P $<0.05$, compared with the blank group. The measurement data are presented as the means \pm standard deviation, which were analyzed by one-way analysis of variance and Tukey's post hoc test. The experiment was repeated independently three times, 10 mice/group. miR-182, microRNA-182; CADM2, cell adhesion molecule 2; NC, negative; siCADM2, CADM2 small interfering RNA.

A

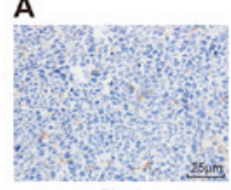

Blank

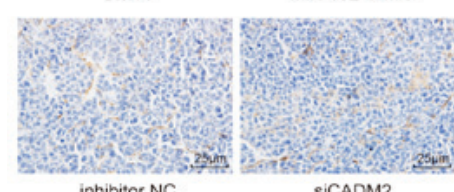

inhibitor NC

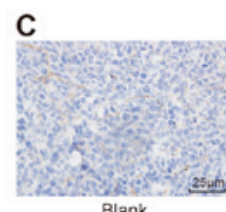

Blank

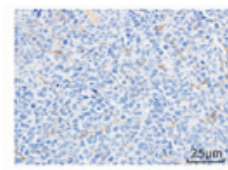

inhibitor NC
SiCADM2

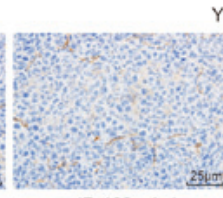

Y79

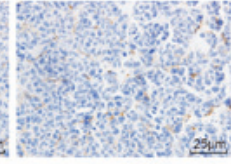

mimic NC

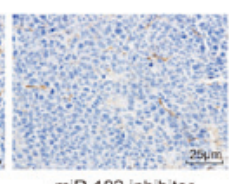

miR-182 inhibitor

WERIRb1

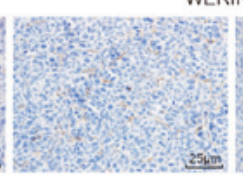

miR-182 mimic

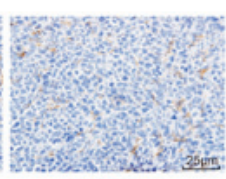

SICADM2

mimic NC
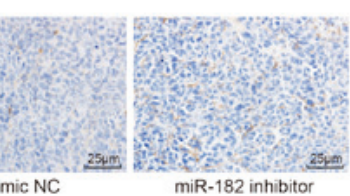

miR-182 inhibitor

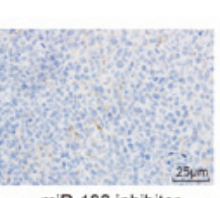

miR-182 inhibitor
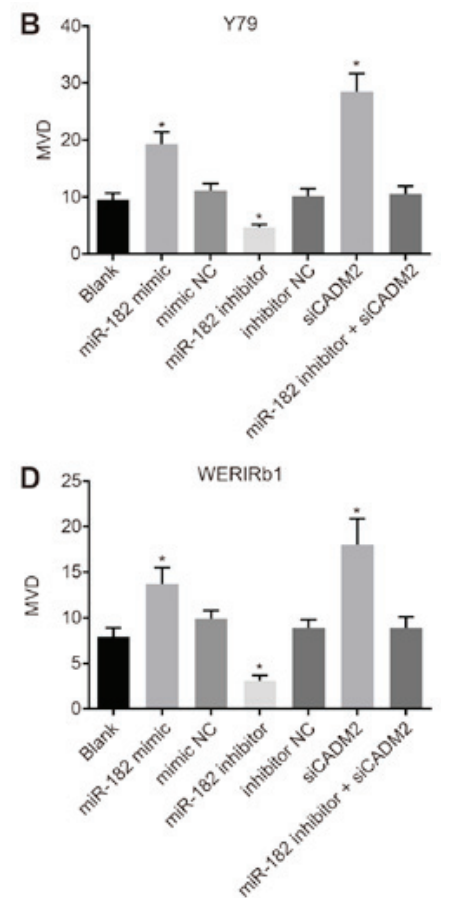

Figure 8. MVD of xenograft tumors in nude mice inoculated with Y79 and WERI-Rb-1 cells is increased by miR-182 overexpression and CADM2 silencing. (A) MVD of xenograft tumors in nude mice inoculated with Y79 cells. (B) MVD of xenograft tumors inoculated with Y79 cells was increased by miR-182 overexpression and CADM2 silencing. (C) MVD of xenograft tumors in nude mice inoculated with WERI-Rb-1 cells. (D) MVD of xenograft tumors inoculated with WERI-Rb-1 cells was increased by miR-182 overexpression and CADM 2 silencing. * $\mathrm{P}<0.05$ compared with the blank group. The measurement data are presented as the means \pm standard deviation, and were analyzed by one-way analysis of variance and Tukey's post hoc test. The experiment was repeated independently three times. MVD, microvessel density; miR-182, microRNA-182; CADM2, cell adhesion molecule 2; NC, negative control; siCADM2, CADM2 small interfering RNA.

significantly elevated tumor weight and volume, whereas the miR-182 inhibitor group exhibited reduced tumor weight and volume $(\mathrm{P}<0.05)$. There was no difference in tumor weight and volume among the blank, mimic NC, inhibitor NC and 
miR-182 inhibitor + siCADM2 groups $(\mathrm{P}>0.05)($ Fig. 7$)$. This observation revealed that xenograft tumor growth in nude mice could be promoted by elevating miR-182 expression.

miR-182 overexpression or CADM2 silencing increases MVD in nude mice inoculated with Y79 and WERI-Rb-1 cells post-transfection. Vascular endothelial cells were labeled with anti-CD34 monoclonal antibodies, and the number of microvessels was detected using immunohistochemistry. CD34 was localized in the cytoplasm of vascular endothelial cells and was presented as pale brown granules. The results demonstrated that, compared with the blank group, the miR-182 mimic and siCADM2 groups exhibited significantly elevated MVD, whereas the miR-182 inhibitor group had reduced MVD ( $\mathrm{P}<0.05$; Fig. 8). There was no difference in MVD among the blank, mimic NC, inhibitor NC and miR-182 inhibitor + siCADM2 groups $(\mathrm{P}>0.05)$. These results indicated that MVD may be promoted by miR-182 overexpression or CADM2 silencing.

\section{Discussion}

A previous study reported that RB has a high incidence in developing countries (22); in addition, several miRNAs are differentially expressed in RB (23). However, it is unclear how miR-182 regulates RB. The present study investigated the effects of miR-182 on RB. The findings provided evidence to suggest that inhibiting miR-182 may activate CADM2 and suppress the PI3K/AKT pathway, thereby suppressing cell viability, invasion and angiogenesis in RB.

In the present study, miR-182 was significantly increased and CADM2 was decreased in $\mathrm{RB}$ retinal tissues. It has been reported that miR-182 is an oncogene (11); miR-182 is upregulated in numerous types of cancer, including non-small cell lung cancer (24). In addition, a previous study provided evidence to suggest that miR-182 is associated with angiogenesis (25). Du et al (26) observed more capillary-like structures in a miR-182 mimic group compared with in a normal group, as determined using an in vitro capillary tube formation assay. Notably, a previous study demonstrated that miR-182 is overexpressed in primary open-angle glaucoma, which is characterized by retinal ganglion cell death (27). CADM2, also known as Nectin-like 3, SynCAM2 and immunoglobulin superfamily, member $4 \mathrm{D}$, is downregulated in numerous types of cancer, including ovarian cancer, prostate cancer, lymphoma and melanoma (28). Consistent with the present results, Yang et al (29) detected low expression of CADM2 in hepatocellular carcinoma. The present study indicated that RB may be associated with miR-182 overexpression and low CADM2 expression. CADM2 is one of the target genes of miR-182. RT-qPCR and western blot analysis revealed that Y79 cells transfected with miR-182 inhibitor possessed significantly decreased expression of PI3K/AKT pathway-associated genes (PI3K and AKT) and the angiogenesis-associated gene VEGF, as well as decreased MVD, but increased CADM2 expression. The majority of cancer types exhibit activation of the PI3K/AKT pathway, including RB (30). A previous study confirmed that miR-182 activates the PI3K/AKT pathway (31), whereas CADM3 inhibits activation of the PI3K/AKT signaling pathway, and CADM3 can bind to CADM4 (32). Non-overlapping expression of CADM2 and CADM3 has been detected in the developing retina, and binding of CADM2 and CADM3 to CADM1 and CADM4 in vitro may indicate the functional role of CADMs during nervous system development (33). VEGF is an angiogenic growth factor that is involved in the pathogenesis of retinal diseases, such as diabetic retinopathy (34). A previous study revealed that VEGF overexpression is associated with RB (35). Furthermore, another study identified that miR-182 overexpression is associated with VEGF-A production and angiogenesis (34). Liu et al (31) suggested that inhibition of miR-182 decreases the level of phosphorylated-AKT. MVD is used to measure angiogenesis, and it has been reported that enhanced angiogenesis appears in miR-182-overexpressing cells $(36,37)$. In addition, it has been revealed that miR-182 targets CADMs (38). These findings indicated that suppression of miR-182 may activate CADM2 and inhibit the activation of $\mathrm{PI} 3 \mathrm{~K} / \mathrm{AKT}$, thus inhibiting angiogenesis in RB.

The present study revealed that miR-182 inhibition reduced cell viability and invasion by activating CADM2 and suppressing the PI3K/AKT signaling pathway, in addition to reducing the expression of proliferation-associated genes (Cyclin E, CDK2 and CDK4) and invasion-associated genes (Vimentin, MMP-9 and Snail). It is well known that miR-182 acts as an oncomiR, which promotes cell proliferation (24). miR-182 overexpression serves a pivotal role in enhancing cell invasion via inhibition of various targets, such as Forkhead box O3, programmed cell death 4 and microphthalmia-associated transcription factor (39). A recent study revealed that CADM2 overexpression suppresses cancer cell proliferation and invasion (28). The PI3K/AKT signaling pathway is a survival pathway essential in apoptosis and cell proliferation (17); it has also been reported that the PI3K/AKT signaling pathway contributes to the proliferation of airway smooth muscle cells (40). In addition, activation of the PI3K/AKT signaling pathway serves an important role in prostate cancer cell invasion (41). A previous study focused on miR-135b, miR-182 and the PI3K/AKT signaling pathway in colorectal cancer (CRC), identifying that overexpressed miR-182 promotes the chemoresistance of CRC by targeting ST6 N-acetylgalactosaminide $\alpha$-2,6-sialyltransferase 2 via the PI3K/AKT signaling pathway (42). Furthermore, the ability of miR-182 to activate the PI3K/AKT signaling pathway has previously been confirmed (31). These findings indicated that inhibition of miR-182 suppressed cell viability and invasion via the activation of CADM2 and by suppressing the PI3K/AKT signaling pathway. Notably, the present findings suggested that cells transfected with miR-182 inhibitor + siCADM2 exhibited similar cell viability and invasive abilities as untreated cells. These findings indicated that CADM2 knockdown may reverse the suppressive effects of miR-182 inhibition on cell viability and invasion.

In conclusion, the present study revealed that downregulation of miR-182 may suppress cell viability, invasion and angiogenesis in RB by upregulating CADM2 and inhibiting the PI3K/AKT signaling pathway. Notably, this study indicated that miR-182 and CADM2 are promising therapeutic targets for RB; however, further studies are required to develop the practical clinical application of these therapeutic targets in the treatment of RB. 


\section{Acknowledgments}

Not applicable.

\section{Funding}

No funding was received.

\section{Availability of data and materials}

The datasets used and/or analyzed during the present study are available from the corresponding author on reasonable request.

\section{Authors' contributions}

YXH, XGN and GDL designed the study. DSF and LLS were involved in data collection. YXH, XGN and XLZ analyzed the data, and reviewed the results and discussion. GDL and DSF collected and provided the samples for the study, prepared the manuscript and revised it. All authors had final approval of the submitted and published versions.

\section{Ethics approval and consent to participate}

Written informed consent was obtained from patients and their families prior to the study. The experiment was approved by the Ethics Committee of Luoyang Central Hospital (Luoyang, China). The animal studies conducted in the present study were approved by the Animal Care Committee at Luoyang Central Hospital.

\section{Patient consent for publication}

Written informed consent was obtained from patients and their families prior to the study.

\section{Competing interests}

The authors declare that they have no competing interests.

\section{References}

1. Carvalho IN, Reis AH, Cabello $\mathrm{PH}$ and Vargas FR: Polymorphisms of CDKN1A gene and risk of retinoblastoma. Carcinogenesis 34: 2774-2777, 2013.

2. Wong JR, Tucker MA, Kleinerman RA and Devesa SS: Retinoblastoma incidence patterns in the US Surveillance, Epidemiology, and End Results program. JAMA Ophthalmol 132: 478-483, 2014

3. Reis AH, Vargas FR and Lemos B: More epigenetic hits than meets the eye: microRNAs and genes associated with the tumorigenesis of retinoblastoma. Front Genet 3: 284, 2012.

4. Yun J, Li Y, Xu CT and Pan BR: Epidemiology and Rb1 gene of retinoblastoma. Int J Ophthalmol 4: 103-109, 2011.

5. Song HB, Park KD, Kim JH, Kim DH, Yu YS and Kim JH: Tissue factor regulates tumor angiogenesis of retinoblastoma via the extracellular signal-regulated kinase pathway. Oncol Rep 28: 2057-2062, 2012.

6. Wang J, Wang X, Li Z, Liu H and Teng Y: MicroRNA-183 suppresses retinoblastoma cell growth, invasion and migration by targeting LRP6. FEBS J 281: 1355-1365, 2014.

7. Xu X, Ge S, Jia R, Zhou Y, Song X, Zhang H and Fan X: Hypoxia-induced miR-181b enhances angiogenesis of retinoblastoma cells by targeting PDCD10 and GATA6. Oncol Rep 33: 2789-2796, 2015.
8. Liu SS, Wang YS, Sun YF, Miao LX, Wang J, Li YS, Liu HY and Liu QL: Plasma microRNA-320, microRNA-let-7e and microRNA-21 as novel potential biomarkers for the detection of retinoblastoma. Biomed Rep 2: 424-428, 2014.

9. Jiang L, Mao P, Song L, Wu J, Huang J, Lin C, Yuan J, Qu L, Cheng SY and Li J: miR-182 as a prognostic marker for glioma progression and patient survival. Am J Pathol 177: 29-38, 2010.

10. Chiang $\mathrm{CH}$, Hou MF and Hung WC: Up-regulation of miR-182 by $\beta$-catenin in breast cancer increases tumorigenicity and invasiveness by targeting the matrix metalloproteinase inhibitor RECK. Biochim Biophys Acta 1830: 3067-3076, 2013.

11. Liu Z, Liu J, Segura MF, Shao C, Lee P, Gong Y, Hernando E and Wei JJ: MiR-182 overexpression in tumourigenesis of high-grade serous ovarian carcinoma. J Pathol 228: 204-215, 2012.

12. Huang M, Xia Z, Wang Y, Huang L, Ma Q, Chen X, Wang H, Lu B and Guo Y: Generation of a monoclonal antibody specific to a new candidate tumor suppressor, cell adhesion molecule 2 . Tumour Biol 35: 7415-7422, 2014.

13. Kandalam MM, Beta M, Maheswari UK, Swaminathan S and Krishnakumar S: Oncogenic microRNA 17-92 cluster is regulated by epithelial cell adhesion molecule and could be a potential therapeutic target in retinoblastoma. Mol Vis 18: 2279-2287, 2012.

14. Brunet A, Datta SR and Greenberg ME: Transcription-dependent and -independent control of neuronal survival by the PI3K-Akt signaling pathway. Curr Opin Neurobiol 11: 297-305, 2001.

15. De Luca A, Maiello MR, D'Alessio A, Pergameno M and Normanno N: The RAS/RAF/MEK/ERK and the PI3K/AKT signalling pathways: Role in cancer pathogenesis and implications for therapeutic approaches. Expert Opin Ther Targets 16 (Suppl 2): S17-S27, 2012.

16. Liu D, Hou P, Liu Z, Wu G and Xing M: Genetic alterations in the phosphoinositide 3-kinase/Akt signaling pathway confer sensitivity of thyroid cancer cells to therapeutic targeting of Akt and mammalian target of rapamycin. Cancer Res 69: 7311-7319, 2009.

17. Cohen Y, Merhavi-Shoham E, Avraham-Lubin BC, Savetsky M, Frenkel S, Pe'er J and Goldenberg-Cohen N: PI3K/Akt pathway mutations in retinoblastoma. Invest Ophthalmol Vis Sci 50: 5054-5056, 2009.

18. Wang B, Shen J and Wang J: UNBS5162 inhibits proliferation of human retinoblastoma cells by promoting cell apoptosis. OncoTargets Ther 10: 5303-5309, 2017.

19. Qi D and Scholthof KB: A one-step PCR-based method for rapid and efficient site-directed fragment deletion, insertion, and substitution mutagenesis. J Virol Methods 149: 85-90, 2008.

20. Ayuk SM, Abrahamse H and Houreld NN: The role of photobiomodulation on gene expression of cell adhesion molecules in diabetic wounded fibroblasts in vitro. J Photochem Photobiol B 161: 368-374, 2016.

21. Livak KJ and Schmittgen TD: Analysis of relative gene expression data using real-time quantitative PCR and the 2(-Delta Delta C(T)) Method. Methods 25: 402-408, 2001.

22. Moreno F, Sinaki B, Fandiño A, Dussel V, Orellana L and Chantada G: A population-based study of retinoblastoma incidence and survival in Argentine children. Pediatr Blood Cancer 61: 1610-1615, 2014.

23. Beta M, Khetan V, Chatterjee N, Suganeswari G, Rishi P, Biswas $\mathbf{J}$ and Krishnakumar S: EpCAM knockdown alters microRNA expression in retinoblastoma--functional implication of EpCAM regulated miRNA in tumor progression. PLoS One 9: e114800, 2014.

24. Ning FL, Wang F, Li ML, Yu ZS, Hao YZ and Chen SS: MicroRNA-182 modulates chemosensitivity of human non-small cell lung cancer to cisplatin by targeting PDCD4. Diagn Pathol 9: 143, 2014.

25. Li N, Hwangbo C, Jaba IM, Zhang J, Papangeli I, Han J, Mikush N, Larrivée B, Eichmann A, Chun HJ, et al: miR-182 modulates myocardial hypertrophic response induced by angiogenesis in heart. Sci Rep 6: 21228, 2016.

26. Du C, Weng X, Hu W, Lv Z, Xiao H, Ding C, Gyabaah OA, Xie H, Zhou L, Wu J, et al: Hypoxia-inducible MiR-182 promotes angiogenesis by targeting RASA1 in hepatocellular carcinoma. J Exp Clin Cancer Res 34: 67, 2015.

27. Liu Y, Bailey JC, Helwa I, Dismuke WM, Cai J, Drewry M, Brilliant MH, Budenz DL, Christen WG, Chasman DI, et al: A common variant in MIR182 is associated with primary open-angle glaucoma in the NEIGHBORHOOD consortium. Invest Ophthalmol Vis Sci 57: 3974-3981, 2016. 
28. He W, Li X, Xu S, Ai J, Gong Y, Gregg JL, Guan R, Qiu W, Xin D, Gingrich JR, et al: Aberrant methylation and loss of CADM2 tumor suppressor expression is associated with human renal cell carcinoma tumor progression. Biochem Biophys Res Commun 435: 526-532, 2013.

29. Yang S, Yan HL, Tao QF, Yuan SX, Tang GN, Yang Y, Wang LL, Zhang YL, Sun SH and Zhou WP: Low CADM2 expression predicts high recurrence risk of hepatocellular carcinoma patients after hepatectomy. J Cancer Res Clin Oncol 140: 109-116, 2014.

30. Mao Y, Xi L, Li Q, Cai Z, Lai Y, Zhang X and Yu C: Regulation of cell apoptosis and proliferation in pancreatic cancer through PI3K/Akt pathway via Polo-like kinase 1. Oncol Rep 36: 49-56, 2016.

31. Liu B, Liu Y, Zhao L, Pan Y, Shan Y,Li Y and Jia L: Upregulation of microRNA-135b and microRNA-182 promotes chemoresistance of colorectal cancer by targeting ST6GALNAC2 via PI3K/AKT pathway. Mol Carcinog 56: 2669-2680, 2017.

32. Chen MS, Kim H, Jagot-Lacoussiere L and Maurel P: Cadm3 (Necl-1) interferes with the activation of the PI3 kinase/Akt signaling cascade and inhibits Schwann cell myelination in vitro. Glia 64: 2247-2262, 2016

33. Kim KH, Lee KY, Lee JB, Yang KS, Hwang J, Je BK and Park HJ: Radiologic factors related to double-bar insertion in minimal invasive repair of pectus excavatum. World J Pediatr 11: $148-153,2015$

34. Akiyama H, Tanaka T, Maeno T, Kanai H, Kimura Y, Kishi S and Kurabayashi M: Induction of VEGF gene expression by retinoic acid through Spl-binding sites in retinoblastoma Y79 cells. Invest Ophthalmol Vis Sci 43: 1367-1374, 2002.

35. Areán C, Orellana ME, Abourbih D, Abreu C, Pifano I and Burnier MN Jr: Expression of vascular endothelial growth factor in retinoblastoma. Arch Ophthalmol 128: 223-229, 2010.
36. Chiang $\mathrm{CH}$, Chu PY, Hou MF and Hung WC: MiR-182 promotes proliferation and invasion and elevates the HIF-1 $\alpha$-VEGF-A axis in breast cancer cells by targeting FBXW7. Am J Cancer Res 6: 1785-1798, 2016.

37. Foote RL, Weidner N, Harris J, Hammond E, Lewis JE, Vuong T, Ang KK and Fu KK: Evaluation of tumor angiogenesis measured with microvessel density (MVD) as a prognostic indicator in nasopharyngeal carcinoma: Results of RTOG 9505. Int J Radiat Oncol Biol Phys 61: 745-753, 2005.

38. Yu B, Qian T, Wang Y,Zhou S, Ding G, Ding F and Gu X: miR-182 inhibits Schwann cell proliferation and migration by targeting FGF9 and NTM, respectively at an early stage following sciatic nerve injury. Nucleic Acids Res 40: 10356-10365, 2012.

39. Spitschak A, Meier C, Kowtharapu B, Engelmann D and Pützer BM: MiR-182 promotes cancer invasion by linking RET oncogene activated NF- $\mathrm{kB}$ to loss of the HES1/Notch1 regulatory circuit. Mol Cancer 16: 24, 2017.

40. Liu Y, Yang K, Sun X, Fang P, Shi H, Xu J, Xie M and Li M: MiR-138 suppresses airway smooth muscle cell proliferation through the PI3K/AKT signaling pathway by targeting PDK1. Exp Lung Res 41: 363-369, 2015.

41. Shukla S, Maclennan GT, Hartman DJ, Fu P, Resnick MI and Gupta S: Activation of PI3K-Akt signaling pathway promotes prostate cancer cell invasion. Int J Cancer 121: 1424-1432, 2007.

42. Jia L, Luo S, Ren X, Li Y, Hu J, Liu B, Zhao L, Shan Y and Zhou H: miR-182 and miR-135b mediate the tumorigenesis and invasiveness of colorectal cancer cells via targeting ST6GALNAC2 and PI3K/AKT pathway. Dig Dis Sci 62: 3447-3459, 2017. 